\title{
How Crm Performs Inside Sales Activities In Itc Companies: A Case Study Of Fincons Group, Italy
}

\author{
Di Vittorio Arianna \\ Associate Professor of Marketing, Department of Economics, \\ Management and Business Law, University of Bari “Aldo Moro”, Italy \\ Di Gioia Vito Alessandro \\ Inside Sales, Fincons Group, Bari, Italy
}

doi: 10.19044/esj.2016.v12n19p312 URL:http://dx.doi.org/10.19044/esj.2016.v12n19p312

\begin{abstract}
The aim of this paper is to take a case study of the Fincons Group and examine the in depth activity of the Inside Sales Department. The study presents Fincons Group, which is an IT Consulting Company. Its offices are based in Italy, Switzerland, and England. They are organized into Business Units and are offering concerns to all the different stages of IT applications as well as complex innovation programs. It explains the activities of the Inside Sales Department, specifically the Inside Sales. In detail, Marketing Analysis and Strategy, Marketing Management, and Marketing Research and Metrics have been considered useful to present to the management the guideline for the quantitative and qualitative analysis of customer relationship management programs. Thus, its aim is to optimize the sales process. This study also deals with CRM Salesforce, which is the IT tool used for customer relationship management. In this case, it is possible to analyse the CRM by going over its list of information. Thus, the aim is to give the guideline to quantify the value of customer relationships. In conclusion, the paper highlights the idea of "Holistic CRM". Specifically, it emphasizes the need for a cross-functional, process-oriented, and calculated approach that positions CRM at a strategic level where business should take precedence over technology.
\end{abstract}

Keywords: CRM, inside sales, performances, ITC companies.

\section{Introduction}

\section{The CRM in Service Industries}

The service sector is receiving much deserved attention resulting from its inevitable role in a country's economic development. Therefore, the service sector is vast. It includes government, health-care, education, 
banking, insurance, finance, consulting, legal, tourism, etc. In considering the intrinsic value of a service which is so called "value in use", the ITC service has become the foundation of every sector in every economy, everywhere. The reasons for these are, by now, fairly well-known. Nevertheless, it demands a brief repetition here. The Information and Communication Technology:

- reduce transaction costs and thereby improve productivity;

- offer immediate connectivity, improve efficiency, transparency and accuracy;

- $\quad$ substitute for other, more expensive means of communicating and transparency, such as physical travel;

- $\quad$ increase choice in the market place and provide access to otherwise unavailable goods and service;

- widens the geographic scope of potential market and channel knowledge and information of all kinds.

During the years, the ITC service has been addressed to get more power. In fact, Nolan and Bennigson" (2003) said: "by the end of the decade, more than 60 percent of the computer communications will be computer-to-computer" and "in the future a high degree of industry adaptation in the IT consulting industry will be required".

Consequently, different ITC tools are used to manage the company business. In addition, they are used for developing B2C and B2B relationships in the marketplace in order to co-create value with the customer and succeed in today's competitive business.

Business-to-consumer (B2C) relationships could be described as a relationship with businesses on the side of supplier and the consumers on the other side. Business-to-Business (B2B) is defined as the form of relationship with the company on the side of supplier and another company on the customer side. To highlight the biggest difference in B2B and B2C relationship, Gummesson ${ }^{84}$ (2008, p. 147) states: "the greater degree of independence between buyers and sellers in the former". In my opinion and according to Gummenson, the difference between B2B and B2C transactions concerns the process and its volume which is usually more complex than B2C market. This case is applicable even if the volume of B2C transaction is increasingly considering e-commerce. Thus, the complexity leans on the number of people responsible for the transaction and the number of steps in

\footnotetext{
${ }^{83}$ Nolan R. \& Bennigson L. (2003, March). The Future of IT Consulting. Harvard Business School Interactive Working Knowledge.

Retrieved from: http://hbswk.hbs.edu/item/the-future-of-it-consulting

${ }^{84}$ Gummesson, E. (2008). Quality, service-dominant logic and many-to-many marketing. The

TQM Journal, 20(2), pp. 143-153. doi: 10.1108/17542730810857372
} 
these transactions. In fact, in B2C relationship, customers are less loyal and are more likely to switch companies. This explains the greater loyalty in B2B relationships and the bigger reliability among trading partners. Concluding the key point analysis, the importance of the B2B market is not just about the product or service, but also about the customer relationship. Furthermore, Johnston and Bonoma ${ }^{85}$ (1981) with reference to the B2B market define the group of people responsible for the transaction as "buying centre" and the transaction process as “decision making”.

The achievement of these relationships is a function of Customer Relationship Management (CRM) implementations within such company. CRM has become a well-known term during the past decade. Brought by academics and implemented into the business by practitioners, it is nowadays well-used in many companies from different industries. Therefore, the difference discussed between B2B and B2C markets and their inbound relationship, shows the evidence that the CRM technology leads to higher performance in $\mathrm{B} 2 \mathrm{~B}$ than in $\mathrm{B} 2 \mathrm{C}$ relationships.

Before understanding the CRM, it is important to underline the relationship between Information Technology and CRM. Thus, three key elements should be taken into account ${ }^{86}$ (Raisch, 2001):

- Customer Touch Points: The interface between the organisation and its customers (i.e. calls, e-mails, websites, videos, TV, retail, etc.) is very vital since the company has a marketing orientation and focuses upon the current and future needs of customers.

- Applications: The software and programmes that support the process.

- Data Stores: It contains data on every aspect of the customer (Customer Life Cycle).

\subsection{CRM Objectives in the IT Sector}

The idea of CRM is that it helps businesses to use technology and human resources to gain insight into the behaviour of customers and the value of those customers. If it works as hoped, a business can: provide better customer service, make call centres more efficient, cross sell products more effectively, help sales staff close deals faster, simplify marketing and sales processes, discover new customers, and increase customer revenues. It does not just happen by simply buying a software and install it. For CRM to be truly effective, an organization must first decide what kind of customer information it is looking for. Also, they must decide what it intends to do

${ }^{85}$ Johnston, W.J. \& Bonoma, T.V. (1981). The Buying Center: Structure and Interaction Patterns. Journal of Marketing, 45(3), pp. 143-156. doi: 10.2307/1251549

${ }^{86}$ Raisch, W.D. (2001). The E-Marketplace: Strategies for Success in B2B E-Commerce. New York: McGraw-Hill. Retrieved from: http://www.marketingteacher.com/crm-andinformation-technology 
with that information. For example, in the IT sector, it is important to keep track of customers' life stages in order to market appropriate IT solutions to potential clients fitting their needs at the right time. At the same time, IT Company must understand why potential clients do not like the IT solution suggested or why clients have changed their IT solution. Next, the organization must look into all of the different ways through which information about customers comes into a business, where and how this data is stored, and how it is currently used. One company, for instance, may interact with customers in a myriad of different ways including mail campaigns, web sites, brick-and-mortar stores, mobile sales force staff, and marketing and advertising efforts. Solid CRM systems link up each of these points. This collected data flows between operational systems (like sales and inventory systems) and analytical systems that can help sort through these records for patterns. In addition, company analysts can then comb through the data to obtain a holistic view of each customer and pinpoint areas where better services are needed.

\section{Fincons Group}

Fincons Group is an IT Consulting Company, established more than 30 years ago. Nowadays, the Group offices are in Italy, Switzerland, and England (Milan, Verona, Rome, Bari, Catania, Lugano, Zurich, Bern, London). The Group Turnover for the year 2015 is more than $€ 80$ million. Thus, it employs more than 1000 people and has more than 250 clients in its portfolio. Fincons Group is organised by business units: Manufacturing, Transportation, Energy \& Utilities, Financial Services (include Banking and Insurance), and Media.

This specific knowledge of each industry allows us to support clients through all the different stages of complex innovation programs. In details, it follows four (4) focal points:

- IT Business Consulting: Acts as consults with feasibility study and cost/benefit evaluation. It suggests the best technology for the clients' business;

- System Integration: System customization through partnership with leading Vendors;

- System Building: It involves the design and development of custom core business solutions, and delivering these solutions in two different ways, "turn-key" or "time-material", on-site or remotely using different technologies such as Web, Mobile, and OpenSource;

- Proprietary Solutions: This includes FiscalOne that supports the management of the company in the complex processes of the calculation of indirect taxes (for the Italian market); Commerce4Media as new tool to sell, manage, and deliver multimedia content online, anywhere and 
anytime; Management of Engagement System as incentive compensation IT solutions for managing the sales-force performance and post-sales services; PerformPA is the software designed to make simple the processes of local governments;

- Application Management: Thanks to the core business process, knowhow, and strong technological expertise which is used possibly to offer IT services and prompt responses to clients' companies all across Europe.

Furthermore, the reason the Fincons Group's services are nowadays even more interesting for Italian and European clients is the "Made in Italy" Smart-Shore model as an alternative to the off-shore version that is useful in managing different time zones and to bridge language gaps. From the Delivery Centre based in Bari (Apulia - Southern Italy), Fincons Group offers services in Application Management and System Building through a work team of 300 dedicated highly qualified graduates ( $90 \%$ graduates able to speak in foreign languages). These graduates have a wide range of technological knowledge, a very low turnover, and a highly tested working methodology. The result is of the highest quality standards for its customers and a competitive cost advantage compared to its competitors. From 2010 to 2015, the turnover of Fincons Group grew by 100\%. In the last 3 years, it has been growing by $20 \%$ each year.

Getting ahead in today's fast-paced business requires companies to be firm-based, flexible, and to have an open mind. Fincons Group has always invested in knowledge, collaborations, research and innovation. The Delivery Centre includes a Business School called the Fincons Group Academy. Thus, its goal is to look for people with a strong IT background in order to build young IT professionals. Through Research and Innovation, Fincons Group keeps abreast of the market trends to help customers make IT innovation a catalyst for development. In fact, the Group is participating in digital transformation projects and is re-designing its offering with omnichannel services, using innovative user experience models. Subsequently, the projects are concerning the Media Business Unit and are going on with the other ones.

The Group also builds a European network of academics, top research centres, and ground-breaking companies for drafting research proposals. In order to achieve its internationalization strategy, the Group has established the International Business Development Unit dedicated to think outside the box. Their aim is to foster strategic innovation, to scout new markets, and to unleash the potential of technology. 


\section{The Inside Sales Department of Fincons Group: The Inside Sales and the Activities Performed}

The Fincons Group has been developing its Inside Sales Department during the last few years. Its purpose is to identify new market opportunities and target the right clients ${ }^{87}$ in order to increase the business of the company.

The activities were initially focused on Southern Italy, relating to:

Acquiring information related to potential clients using online resources such as internet searches, referrals, or offline databases.

$>$ Developing one-to-one relationships with potential clients, by using coldcalling as well as email presentations and on-line presentations;

$>$ Examining the ICT scenario of the client through short surveys, in order to position the offering of Fincons Group, targeting the client, and starting the follow-up valuation.

Considering the positive results of doing business just in Southern Italy, all operations of the Inside Sales Department have been extending across Italy and probably in the future in Europe too.

For this purpose, a specific plan has been developed in order to optimize all operations. Specifically, these operations include:

$>$ Improving scouting techniques such as preparing customized scripts, acquiring the know-how to better qualify a potential client $\left(\mathrm{BANT}^{88}\right)$, creating specific presentations, and detailed documents and reports.

$>$ Standardizing activities by setting up procedures and methodologies to better manage the flow of information in order to monitor all feedback conversations and share the opportunities with the Management.

$>$ Updating the tools that are useful to the activities of customer relationship management.

In this scenario, I have joined the Inside Sales Team as Inside Sales ${ }^{89}$. However, the activities concern the "Sales Process" and are organized in relation to the company mission, timeline, and deadlines ${ }^{90}$.

87 The meaning of "client" and "customer" is different; but in this paragraph, the words are synonymous in order to follow the economic indicator used to analyse the business performance (i.e. Customer Lifetime Value)

${ }^{88}$ B.A.N.T.: It is a method of assessing the quality of potential client and tracking them through the sales qualification process; Need (What are the needs or conditions that have to exist before our service would be valuable to a potential customer?); Budget (How much money must be available in the customer's budget to buy our service?); Authority (Does this person have the authority or can they get approval to make a buying decision?); Timing (Does the timing of the purchase fall within the timeline of the sales rep's commission plan? If it does not, sales reps will have little incentive to pursue the lead).

${ }^{89}$ The Inside Sales is a professional in sales, and they are able to prospect market opportunities, identify customer needs, and manage different communication channels and tools. In detail, the inside sales is suggesting solutions by combining hard and soft skills and industry expertise in order to build and nurture profitable relationships with potential clients. 
In the short-term, the activities include:

- Qualification: This is the activity in relationship with the question "who our target is"? From this starting point, the inside sales looks for information that are useful to qualify the potential client, that is the person, as suspect ${ }^{91}$ or lead ${ }^{92}$ and the company as prospect ${ }^{93}$ or client. This details is about the company (i.e. business unit, turnover, country, etc.) and the potential client (i.e. his or her professional contacts such as email, office telephone number, direct mobile, address, etc.).

- Updating data on CRM.

In the medium and long-term:

- Scouting by contacting potential new clients that could be interested in Fincons Group services and with their implementing "customer engagement strategies ${ }^{94}$ (Kotler et al., 2014)".

- Nurturing: The process of "pursuing” the suspect client and in particular, providing customized information in a specific time (i.e. providing updates on the company, new success histories, notes on coming events, etc.), considering all the information useful to better position the Fincons Group services in the mind of the potential client as well as in the market.

At the core of the process, there is the potential client. However, the Inside Sales Department goal is to transform this one from a potential client to a business opportunity. In some cases, this process can go on for several months ${ }^{95}$.

${ }^{90}$ In my opinion, it is the difference between the inside sales and the telemarketing operator. The telemarketing activity is developed especially in B2C market on random contact information which is publicly available. No inside sales department puts purchased contact information lists at the centre of its strategy. Inside sales department find the right characteristics through searches oriented to qualifying and targeting the potential clients. Furthermore, Inside sales department could be oriented to develop customer engagement strategies in order to improve the company performance. Nowadays, marketers need to anticipate or provide real-time and personalized experiences that reach customers just as they need them.

${ }^{91}$ A suspect is a name and a name only. In fact, it may only be the name or if you have a name, you might not be certain if this person is appropriate for your business. You only suspect this "entity" would be appropriate for your products or services.

${ }^{92}$ A lead is the person you have established a future with. It might not be immediate, but it is a possible business. If you have a name, it may be a visitor of your web-site who has downloaded the information, somebody who has received an e-newsletter, a reader of your publication, an attendee at a trade event, etc.

${ }_{93}$ In our case, a prospect is a company where we have established a possible business opportunity.

${ }^{94}$ Kotler P., Keller K.L., Ancarani F. \& Costabile M., (2014). Marketing per Manager. Capire il Marketing Made in Italy, (1st Ed.) Pearson.

${ }^{95}$ By the opinion of the authors, the point is crucial considering the fact that even if the marketing operations and inside sales operations are different, they have a converge on the business opportunity for the company. From this prerequisite, it could be useful to clarify 
The Customer Lifetime Value is the amount of profit the company can expect to generate from a customer from the time the person (or company) remains a customer (i.e., " $x$ " number of years). At its core, the CLV is the potential value of all future profit that an individual customer will generate over the life of their business with the firm.

Consequently, we can estimate the cost of acquisition for a potential customer and compare this with the benefits expected during that period. Specifically, the CLV depends on three key features ${ }^{96}$ (Steenburgh \& Avery, 2010, pp.1-2; Gupta \& Lehemn, 2003, p.10-13):

- The cost of acquisition for each customer based on qualification activities, scouting, nurturing (customer relationship program), and marketing programs.

- The annual profit the customer generates for the firm: Profit is a function of the revenue generated by sales, and it is influenced by variable costs that the company may incur to "serve the customer".

- The number of years the customer is likely to purchase from the firm: This is achieved by considering different sales periods for each customer.

Considering these assumptions, the CLV formula is as follows:

$$
\mathrm{CLV}=\mathrm{m} * \mathrm{~L}-\mathrm{AC}
$$

where,

$\checkmark \mathrm{m}$ : Is the contribution margin generated from one customer in one year (or period elected $)^{97}$

$\checkmark$ L: Is the expected purchasing life of a customer (measured in years if the annual contribution margin is beginning to be used),

$\checkmark$ AC: Is the up-front cost of acquiring a customer, remembering that common sense suggests that the cost incurred by a company with customer acquisition should not be more than his or her life-time value.

By taking an in depth examination of the customer, a further index is necessary to analyse: The Retention Rate.

the meaning of lead generation. For example, for the Marketing Department, it could remain "lead generation" according to academic definition. For the Inside Sales Department, it could be changed into "meeting generation". In both cases, the goal is just one: to generate business opportunity.

${ }^{96}$ Gupta, S. \& Lehemn, D.R. (2003, November). Customers As Assets. Journal of Interactive Marketing, Vol 17. pp.9-23. doi: 10.1002/dir.10045

Steenburgh, T. \& Avery, J. (2011, August). Marketing Analysis Toolkit: Customer Lifetime Value Analysis. Harvard Business School Publishing. pp. 1-9

${ }^{97}$ Contribution Margin is the selling price per unit minus the variable cost per unit. "Contribution" represents the portion of sales revenue that is not consumed by variable costs and so contributes to the coverage of fixed costs. This concept is one of the key building blocks of break-even analysis. 
It is the percentage of customers who maintain the relationship with the company in a given period, and the formula is given as follows ${ }^{98}$ (Busacca et al., 2008):

where,

$$
\mathrm{RR}=((\mathrm{EC}-\mathrm{NC}) / \mathrm{CS})) \mathrm{X} 100
$$

$\checkmark$ EC: Number of customers at end of period

$\checkmark$ NC: Number of new customers acquired during a period (e.g., 1 year)

$\checkmark$ CS: Number of customers at the start of period

A customer today appears faithful and loyal, but during the relationship, the customer no longer feels satisfied by the performance of the company. As a result, he decides to turn to another company. Every customer lost is almost always won by the competitor. This is the reason why it would be appropriate to control the Churn Rate of the customers (Steenburgh \& Avery, 2010, p.3).

The formula is as follows:

$\mathrm{CR}=$ Clients lost during the period / Clients at the start of the period

Customer Lifetime Value, Customer Retention, and Churn Rate would provide management with a guideline to define the cost of implementing a customer relationship management program, and more specifically, to improve customer satisfaction, and to give new keys to increase the value proposition $^{99}$.

\section{The CRM Salesforce as a Work Tool}

An IT tool is necessary to manage the Inside Sales Department operations. The CRM Salesforce is the IT application adopted by Fincons Group. Through the help of Salesforce, the Inside Sales Department is able to manage and analyse customer interactions and data throughout the customer lifecycle. However, this is with the goal of improving business relationships with customers, assisting in customer retention, and driving sales growth.

Specifically, it is possible to ${ }^{100}$ (Sarvary, M. \& Elberse, A., 2006; Venkatesan, R., 2007):

98 Busacca, B., Costabile M. \& Ancarani, F. (2008). Creating and managing superior customer value. Advances in Business Marketing and Purchasing. Vol.14, pp. 149-204. doi: 10.1016/S1069-0964(08)14005-4

${ }^{99}$ Value Proposition: It is an analysis or statement of the combination of goods and services offered by a company to its customers in exchange for payment.

[VP = Benefits * Perceived Performances / Costs * Expensiveness]

Retrieved from: Costabile, M. (January-February 2012). MBA Student Book. Subject: Marketing Analysis and Strategy. Luiss Business School,

${ }^{100}$ Sarvary, M. \& Elberse, A. (2006, April). Market Segmentation, Target Market Selection and Positioning. Harvard Business School Publishing. pp. 1-5 
- Start market segmentation and target market selection based on the customer characteristics relevant to the business of the Fincons Group and to the marketing and sales efforts.

- Identify customer needs: This can be achieved by getting to know your customer in depth by scouting and nurturing activities, in order to learn which customer has the highest profit potential.

- Managing contacts over time by considering internal changes in the client's company as well as the different role of each manager in taking decisions (e.g., CIO, IT Manager, Purchasing Manager, etc). Also, it could be possible to deal with different people during activities such as qualification, scouting, nurturing, etc.;

- Increasing profit and referrals from existing customers: This is done by managing up-selling and cross-selling ${ }^{101}$ strategies in order to implement customer retention.

- Improving Fincons Group services: Through CRM, it is possible to collect data from calls, e-mails, presentations, meetings, and from different sources such as official websites, blogs, social media, etc.

- Measuring and optimizing the performance of Inside Sales Department Team by getting the insights necessary to make the best decisions.

Subsequently, let it be clear that the information generated by qualification, scouting, and nurturing activities is the starting point. To emphasise this first point, it is interesting to note the expression that appears on the Salesforce website: "every member of your sales team has the information they need to make the right pitch at the right time".

However, the information might not be enough. To be able to use CRM, paying attention to the quality of the information could create the competitive advantage. The assumption is the value of customer relationships, which is defined as the sum of the values of current relationships and the value of potential relationship.

To quantify this value, the following formula could be useful, which should be used in relation to the available data for Fincons Group ${ }^{102}$ (Vicari et al., 2000):

\footnotetext{
Venkatesan, R. (2007). Cluster Analysis for Segmentation. Darden Business Publishing. pp. 1-8. Reference n. uva-m-0748. Designed for use in an Darden MBA marketing research course.

${ }^{101}$ The up-selling: Sales technique that aims to offer the consumer something of greater value than its choice of initial purchase; Cross-selling: It aims to increase the value of the exchange by providing products or services related to the choice of initial purchase, making it more complete.

${ }^{102}$ Vicari S., Bertoli G., \& Busacca B., (2000). Il valore delle relazioni di mercato. Nuove prospettive nell'analisi delle performance di mercato. Finanza Marketing e Produzione, n. 3.
} 
$\mathrm{Wrc}=\mathrm{Wra}+\mathrm{Wrn}$

- Wra refers to current relationships, depending on:

$\checkmark$ Retention rate: The percentage of customers who have relations with the company during one specific time.

$\checkmark$ Longevity of current relationships: The expected life in relationship with ratio of retention.

$\checkmark$ Actualization factor ${ }^{103}$.

- Wrn refers to future relations, depending on:

$\checkmark$ Coefficient to attracting new customers: company's ability to expand the network.

$\checkmark$ Contribution margin generated by new customers, just considering net acquisition costs.

$\checkmark$ Actualization factor.

As an IT application, the CRM allows us to get to know the market of the company, in this case, Fincons Group. By collecting data with objective criteria, it is possible to calculate the Market Potential, Market Demand, Market Gap, and much more to cluster data and proceed to Market Segmentation for each Business Unit or new IT application branded Fincons Group, eventually estimating the Company Sales. Again, it will only be possible in relation to the amount of data, as much as the quality of the information that Fincons Group collected.

\section{Conclusion}

My Master in Business Administration has given me a deep analysis about Fincons Group, its Inside Sales Department, the Inside Sales activities, and the Sales Process. It suggests that the Inside Sales activities can have an update in relationship to the market development. Also, the CRM can go beyond the IT vision.

The idea is that CRM refers to the company as a whole. It is a management process. Through the achievement of organizational efficiency, it allows increase in the company's revenue.

In fact, some case studies allow us to hypothesize that the competitive value, generated by implementing the "CRM Oriented" approach, will be effective at a time when, among all company departments, there is a homogeneity about the methodology of approach. Through this way, it is possible to avoid the risk of assembling individual plans that

(Passaro. P., La Prospettiva Olistica del Customer Relationship Management, 2012, Franco Angeli)

${ }^{103}$ Actualization factor is the following value $1 /(1+r)$. It corrects the cash flow compared to the period in which it is determined. 
correspond more to a tactical than a strategic approach ${ }^{104}$. The idea is to decide "where and how to use CRM" asking questions such as: Is it strategic? Where in customer-relationship problem arise? Considering is it possible to calculate different indexes, does the Inside Sales Team needs perfect data? If so, which data is the most essential? Where does the Inside Sales Department goes from here-today?

Answering to these questions means to understand the "CRM as Holistic" where the focus will be first on "customer engagement" through listening and communications skills, as well as technical and managerial skills. These skills, thus, refer to different company departments, with each one paying attention to the limits of its operation so as to avoid the trap of the micro-management.

In conclusion, it will be important to emphasize the need for a crossfunctional, process-oriented, and calculated approach that positions CRM at a strategic level where business should take precedence over technology.

\section{References:}

Busacca, B., Costabile M. \& Ancarani, F. (2008). Creating and managing superior customer value. Advances in Business Marketing and Purchasing, Vol.14. pp. 149-204. Emerald Group Publishing Limited. doi: 10.1016/S1069-0964(08)14005-4

Costabile, M. (January-February 2012). MBA Student Book, Subject: Marketing Analysis and Strategy. Luiss Business School

Customer Engagement: Best of the Best. (2015, January) Forbes Insights sponsored by SAP. Retrieved from: www.forbes.com/forbesinsights/sap_customer_engagement/index.html

Dolan, R. J. (November 1, 2000). Note on Marketing Strategy. Harvard Business School Publishing.

Gummesson, E. (2008). Quality, service-dominant logic and many-to-many marketing. The TQM Journal, 20(2), pp. 143-153. doi: 10.1108/17542730810857372

Gupta, S. \& Lehemn, D.R. (2003, November 1). Customers As Assets. Journal of Interactive Marketing, Vol 17. pp.9-23. doi: 10.1002/dir.10045 Johnston, W.J. \& Bonoma, T.V. (1981). The Buying Center: Structure and Interaction Patterns. Journal of Marketing, 45(3), pp. 143-156. doi: $10.2307 / 1251549$

Keiningam T., Aksoy L., Cooil B. \& Andreassen T.W. (2008, July 1). Linking Customer Loyalty to Growth, in MIT Sloan Management Review.

104 Tactic is an option that the company might use that is comparatively easy and inexpensive to deploy. It differs by a strategy that is the plan according to a set of activities used to create a valuable position in the market. 
Kotler P., Keller K.L., Ancarani F., Costabile M., (2014, $1^{\text {st }}$ ed.) Marketing per Manager. Capire il Marketing Made in Italy. Pearson.

Nolan, R. \& Bennigson, L. (2003, March). The Future of IT Consulting in Harvard Business School Interactive Working Knowledge. Retrieved from: http://hbswk.hbs.edu/item/the-future-of-it-consulting

Payne A., \& Frow P., (2005, October) A Strategic Framework for Customer Relationship Management. Journal of Marketing. Vol. 69, No. 4, pp. 167176. doi: http://dx.doi.org/10.1509/jmkg.2005.69.4.167

Sarvary, M. \& Elberse, A. (2006, April). Market Segmentation, Target Market Selection and Positioning. Harvard Business School Publishing. pp. $1-5$

Ross, S., Westerfield, R. \& Jordan, B.D., (2008, 9th ed.) Fundamentals of Corporate Finance. McGraw-Hill/Irwin Hardcover. (Chapter 1)

Steenburgh, T. \& Avery, J. (2011, August). Marketing Analysis Toolkit: Customer Lifetime Value Analysis. Harvard Business School Publishing. pp. $1-9$

Venkatesan, R. (2007). Cluster Analysis for Segmentation. Darden Business Publishing. pp. 1-8. Reference no. uva-m-0748. Designed for use in an Darden MBA marketing research course.

Vicari S., Bertoli G., \& Busacca B., (2000). Il valore delle relazioni di mercato. Nuove prospettive nell'analisi delle performance di mercato", Finanza Marketing e Produzione, n. 3. (Passaro. P., 2012, La Prospettiva Olistica del Customer Relationship Management, Franco Angeli) 